\title{
建構道教器官捐贈現代教義詮釋
}

\section{Constructing Modern}

\section{Interpretations of Daoist Views}

\section{Concerning Organ Donations}

\author{
余定檉 \\ Yu Ding Ching
}

摘要 Abstract

道教以不老不死成仙為終極關懷。隨著科學發展和宗教互 涉, 部份道派已放棄今世肉體永活的基要信仰, 轉而信奉輪迥 轉世, 但是道教生命觀仍然重視身體的保養和修煉, 如何在古 老成仙終極關懷和現代器官捐贈議題中取得平衡, 需要重新詮 釋教義。然而, 道教教義縱向有時代轉變, 横向有派別不同, 必須整體綜觀才能抽取其中必要而共通的元素, 繼而以之思考

余定檉, 香港大學附屬學院兼任講師; 中山大學哲學系博士研究生畢業, 中國廣 州, 郵編：510275。

Yu Ding Ching, Part-time Lecturer, HKUSPACE Community College of the University of Hong Kong, Hong Kong, China; Doctor Graduate, Department of Philosophy, Sun Yat-sen University, Guangzhou, China, 510275.

《中外醫學哲學》XIX:1 (2021 年) : 頁 97-109。

International Journal of Chinese \& Comparative Philosophy of Medicine 19:1 (2021), pp. 97-109.

(C) Copyright 2021 by Global Scholarly Publications. 
器官捐贈的議題。因此, 下文將梳理歷代道經文獻, 應用宗教 現象學的概念, 系統分析主要道派對器官捐贈的可能態度及成 因, 並提出器官捐贈的教義現代詮釋以供參考：現今道教普遍 依然相信人生是樂, 追求延壽消災, 正一道全真道等主要派別 均信奉星斗信仰經典, 因此其中《太上玄霝斗姆大聖元君本命 延生心經》的身體觀可視為共通教義, 它將輪迥主體定位於人 體中心, 按現代醫學大可定義為腦髓, 活體或遺體器官捐贈, 因此均不會對捐贈者或受贈者的轉世投胎有負面影響。而且, 道教善於向社會主流道德倫理價值觀屈服, 現今維護人權和同 理心均是全球主流道德倫理價值觀。活體器官捐贈可利益他人 活命或有善功以助成仙, 但也或會阻礙自身修行進程, 如何抉 擇應尊重個人的主動性意願。

The ultimate concern of the Daoist religion is becoming an immortal with eternal youth. Yet with the influence of modern scientific development and increasing interactions between different religions, some Daoist sects have given up the old doctrine of immortality and replaced it with the Buddhist tenet of reincarnation. Nevertheless, Daoism is facing a moral dilemma between its deeply held idea of the somatic cultivation of the body and the modern idea of organ donation. In this paper, the author interprets Daoist texts through the lens of phenomenology of religion and explores the possible reconciliation between traditional Daoist practice and the practice of organ donation. The paper shows that different Daoist sects hold different opinions, but that in general, Daoism grants agency regarding the decision to the individual practitioner.

【關鍵字】仙肉身 魂隗神 輪迴 遺體器官移植 活體器官移植

Keywords: Daoism, immortality, bodily practice, reincarnation, organ donation

部份佛教徒認為人死後八小時內神識尚存, 仍能知覺苦痛、 生起嗔怒和積累惡業, 從而影響投胎。(梁辰, 鄧莣 2018，52) 雖 
然此説並非佛教界的定論，(孫穎 $2018 ， 6$ ) 但現實上對遺體動刀 不可能麻醉, 佛教徒考慮捐贈器官不免因而有所困擾。道教生命 觀深受佛教影響, 重視身體比佛教猶尤甚, 如何在古老成仙終極 關懷和現代器官捐贈議題中取得平衡, 需要重新詮釋教義。然而, 道教教義縱向有時代轉變, 横向有派別不同, 必須整體綜觀才能 抽取其中必要而共通的元素, 繼而以之思考器官捐贈的議題。因 此, 下文將先梳理歷代道經文獻, 應用宗教現象學的概念, 系統 分析主要道派對器官捐贈的可能態度及成因, 最後提出器官捐贈 的教義現代詮釋以供參考。

\section{一、遺體器官捐贈：在礙成仙到助成仙之間}

東漢早期天師道認為世人分為“賢者” 和“俗人”。“賢 者” 示死而並非真正死去, 而是在泥土之下 “避去託死”，經歷 “太陰煉形” 便會 “復一邊生像, 沒而不殆”，假死之時保存身 體因此有其必要, 因為身體修補復原後便會成仙。相反“俗人” 則是 “死便真死”，(饒宗頣 1956，22) 遺體腐朽無用，器官捐贈 無妨。而太平道的《太平經》則認為 “人人得一生, 不得重生也”, 要成仙機會只有此生, 成不了仙遺體便會朽壞, “脈骨成塗土”。 依此而言, 遺體器官捐贈絕對可以。然而, 經中也談及死而復生 的得道人, “重生者獨得道人, 死而復生, 尸解者耳”及 “户在 一身, 精神為人, 户使人見之, 皆言已死。後有知者, 見其在, 此尸解人也”; (王明 $1960 ， 340 ， 298$ 及 553) 魏晉金丹道葛洪《抱 朴子》同樣認為 “上士舉形昇虛, 謂之天仙。中士游於名山, 謂 之地仙。下士先死後蜕, 謂之尸解仙”。綜合而言, 尸解成仙者 是身體死去 ( “P在一身” 或 “先死後蜕”) , 精神成仙 ( “精神為 人”) ; 而成不了仙的人 “魂隗……盡去則人死”，(王明 1980 , 18, 19-20) 他們兩者的遺體器官同樣也是捐贈無妨。問題是, 我們 無法辨別死者是屬於太陰煉形還是先死後蜕, 旁人無法辨別死者 是真死還是假死, 如果死者未有言明意願而由家屬決定遺體器官 
捐贈, 則或會障礙或斷絕其復生過程。可是現行遺體器官捐贈, 大多情況捐贈者在世時曾明確表明意願, 而且傳説中行將太陰煉 形的高士, 自會尋找俗人難以打擾之處安置肉身; 六朝時上清派 更主動以自焚、投水、受刃、服毒等自殺方式來尸解求仙, (韓吉 紹 2017，30) 遺體器官捐贈因而更為可行。

自上清派及靈寶派起，道教便吸收了佛教死後輪迴的思想， 輪迴主體卻非佛教暫存假立的阿賴耶識, 而是永存不滅的 “神”、“魂”或 “魄”。上清派《太上老君內觀經》認為心為 “一身之主”、“心則神也……所以流浪生死, 沉淪惡道, 皆由 心也。”(《道藏》11：396) 心神乃是輪迴主體；靈寶派《洞玄靈 寶諸天世界造化經》也認為 “眾生死時, 形滅而神移, 皆緣其生 時所作罪福, 至彼五道之處。” (《道藏》5：861) 但也有靈寶經 認為魂隗是輪迴主體, 魂魄離人體便立即斷氣, 《太上洞玄靈寶 業報因緣經》認為 “人欲終亡之時……勅下三界官屬、四司五帝 收其魂隗, 絕其生氣矣。”(《道藏》6：118) 重玄派《太玄真一 本際經》有 “魂昇南宮, 不入三途, 還生善道”之語, 按校 “魂” 字於《三論元旨》中作“神”，(葉貴良 2010，19) 可見魂或神為 輪迴主體。總之魏晋至唐的主要道派, 多認定神魂隗為輪迴主體, 少量道經更兼而談及輪迴主體離體時間為斷氣一刻。

隨著晚唐五代佛教疑偽經《佛説十王經》盛行, 道教吸收了 佛教亡者死後四十九日內, 為其打齋積德影響投胎趣向的信仰。 曾慥編集的《道樞》繼而收有出現 “是以人生四十九日而七魄全, 其死則四十九日而七魄絕” 的思想, (《道藏》20:671) 此死後每 七日一魄離體之説, 可能妨礙遺體器官捐贈, 因挪去器官或會影 響投胎。然而, 南宋出現拔度亡者的濟煉科儀後, 卻可發現《道 樞》之説只屬小眾, 影響力大的典籍如東華派《靈寶領教濟度金 書》卷十一、卷二八、卷八六及卷七四中，均有召喚亡者輪迴主 體來臨道場、觀聽法音以超脱的 “冥府引將魂 (隗) 來” 或 “陰府 迎將淨魂 (隗) 來” 等句。(《道藏》7：99，165 及 $337 ； 8: 41$ ) 其 
中第六字或是魂或是隗, 本文認為這反映了魂魄在南宋中後期, 已被視為會在斷氣後一併下降冥府。就後世道教徒而言, 除非執 意信奉《道樞》七隗逐一離體之説, 否則遺體器官捐贈不會損害 輪迴轉世。

另外，靈寶派大量移用佛教 “大乘”一詞。(謝世維 2012， 3) 大乘菩薩慈悲普渡被改造成《度人經》的 “仙道貴生, 無量度 人”; (《道藏》 $1: 5)$ 北宋神霄派將一卷《度人經》敷演至六十 一卷, 以皇權拔高度人思想; (《道藏》1 : 9-416) 南宋淨明道雖 以儒家忠孝修仙, 但《淨明忠孝全書》載 “何謂一? 太上之淨明, 夫子之忠恕, 翟曇之大乘, 同此一也。” (《道藏》24：645) 將忠 恕等同大乘行 ; 金元全真道《三州五會化緣榜》主張 “先人後 己”，實踐 “修仁蘊德，濟貧救苦，見人患難常行拯救” 的 “真 行”。(《道藏》25:788) 加上《金關玉鎖訣》 “唯一靈是真, 肉 身四大是假, 相借煉假成真”。(《道藏》25：799) 明確拋棄了永 保肉身以成仙的原教旨信仰, 認為一切人類包括成仙者, 今世肉 身都終將腐朽。總而言之, 遺體器官捐贈對上述道派而言, 不但 可以更應提倡, 既助投胎善道也助積善成仙。雖然, 在終極關懷 上度人指度人成仙, 但器官捐贈延長壽命或減輕痛苦, 也為他人 爭取更長或更高質素的在世時間, 用以修行或由他去再作普渡。 依此才有香港道教聯合會認為 “軀體只是臭皮囊而已”，重生與 否取決於生前 “道” 與 “德”，不受器官捐贈影響。(香港器官移 植基金會 2017，83)

\section{二、活體器官捐贈：在礙修行到助修行之間}

現行活體器官捐贈實際上只涉及腎臟、部分肝臟、部分肺 臟、部分胰臟或部份小腸的移植。活體器官捐贈是否合宜, 需要 從三個層面考慮, 一是會否負面影響捐贈者修煉成仙; 二是會否 負面影響捐贈者及受贈者輪迴轉世; 三是如何平衡利益他人存活 治病與減損自己成仙機會兩者。 
首先，關於捐贈者修煉成仙會否受負面影響。太平道修仙方 法多元，與人體器官有關的修仙方法 “守一” 就有 “肉之一者， 腸胃也。能堅守，知其道意” 的概念，(王明 1960，13) 如修此仙 法則活體捐贈部份小腸或有妨礙; 天師道則認為因為 “古仙士寶 精以生，今人失精以死”，修煉成仙應該 “結精成神……人之精 氣滿藏 (臟) 中”，捐贈活體器官明顯有損精氣，而且 “五藏 (藏) 以傷，道不能治”，其傷害不能逆轉。(饒宗頣 1956，29，12 及 7) 然而, 經文只提五藏不論六腑, 捐出腎藏、部分肝藏或部分肺 臟斷然不可, 部分胰臟或部分小腸則或可, 後者只屬腑器而非藏 器; 金丹派《抱朴子》認為成仙的必要條件為服食金丹，箇中原 理是 “假求於外物以自堅固”，而 “服金者壽如金，服玉者壽如 玉也”，(王明 1980，62 及 185) 人可吸收外物的屬性，金玉不朽 服之已可延壽。金丹燒煉結合陰陽, 更是逆向模擬天地開闢造化, 含有 “肇始、起源、太初意義”，宗教人普遍相信生命日益消耗 “不能復原, 只能藉重現宇宙開闢來重新創造”, (耶律亞德 $2000 ， 70 ， 20$ 及 71) 服食金丹即可更新人體小宇宙。既然要以外 物堅固自身, 又要回到原初圓滿, 活體捐贈器官缺損臟腑、弱化 體能似乎便違背了其宗旨, 但《抱朴子》同時認為積善對成仙有 必要性, “欲求仙者, 要當忠孝和順信義為本” 及 “積善事未滿, 雖服仙藥，亦無益也。” (王明 1980，47-48) 忠孝信義是儒家家庭 外延式倫理, 活體器官捐贈多以家人為對象, 在確有必要時似乎 捐贈才是修仙正途; 上清派將守一發展成存思法, 並視為首要修 仙法。存思法認為身體各處駐有小型身神, 仔細幻想其名字長短 顏色, 便能令祂們長駐身中, 卻病不老成仙。梁丘子《黃庭內景 玉經注》説明 “外象諭即日月、星辰、雲霞之象; 內象諭即血肉、 筋骨、藏府之象也。心居身內, 存觀一體之象色, 故曰內景也。” (《道藏》6：516) 因為“創造起源自宇宙中心”, (耶律亞德 2000, 14) 將人身小宇宙對應大宇宙, 便能篗取強大的生命力。活體器 官移植與上清派核心修法或有相左, 缺損人體小宇宙會令身神離 
體致病。《太微帝君二十四神回元經》記載左腎神 “名春元真, 字道卿, 形長三寸七分, 數變, 白赤青五色無常”, 右腎神 “名 象地無, 字道生, 形長三寸五分, 白或黑”。(《道藏》34：774) 捐去部份器官其中身神或尚可勉強居處, 但捐去整個腎臟則腎神 會離體而去; 靈寶派則相信大梵之丕結成的天書經文總含宇宙初 開的神奇法力, 原理與上述原初創世時間原型相同不再贅述, 人 只要齋醮誦經即可成仙, 在世時只要不損聲帶和肺功能, 捐去器 官大多無損修行。

第二，負面影響捐贈者及受贈者輪迴轉世與否，要考慮移植 過程會否損害兩者的輪迴主體。漢朝黃老道《老子河上公章句》 繼承《素問》臟腑五行説, 認為“肝藏魂, 肺藏隗, 心藏神, 腎 藏精，脾藏志，五藏 (臟) 盡傷，則五神去矣”，(王明 1948，16) 但黃老道並未視魂魄神為輪迴主體; 上清派《太上老君內觀經》 雖看似沿用黃老道五神説, 但卻認為五神是心神於五藏變化運用 時的不同稱呼而己, “心則神也, 變化不測, 故無定形。所以五 藏 (藏) 藏五神, 魂在肝, 魄在肺, 精在腎, 志在脾, 神在心, 所 以字殊, 随處名也。”(《道藏》11：396) 經文有意識地改造舊説, 將輪迴主體 “神” 重置於心臟, 心神只是作用於肝肺腎脾並未依 附其上, 因此割下的活體器官, 並不會仍盛載著捐贈者的 (部分) 輪迴主體, 受贈者並不會因移植器官而一併接收對方的輪迴主 體, 影響自身輪迴主體的純淨性。總之, 捐贈者及受贈者的輪迴 主體及轉世都不會受到負面影響。

第三，關於如何平衡利益他人存活治病與損傷自己成仙機會 兩者, 太平道認為積極行善積功累德也是修行的仙法之一, (林富 士 2009, 217) 活體捐贈器官利人雖可能妨礙器官相關的仙法如守 一的修行, 但利益孰輕孰重實難分高下; 天師道也重視行善積功, 《老子想爾注》載 “是以人當積善功, 其精神與天通。設欲侵害 者, 天即救之。” (饒宗頤 1956，8) 但畢竟未比藏精的五臟捐傷 不能恢復嚴重; 淨明道以實踐忠孝德行作為成仙的手段, 活體捐 
贈器官捐贈者及受贈者多為親屬, 以活體捐贈器官救活父母長上 同時正是修仙實踐, 相得益彰; 然而, 全真道以人身中的 “真水” 和“真火”修煉返回原初創世時間原型的內丹，《鍾呂傳道集》 記載 “腎, 水也; 水中生氣, 名曰真火……心, 火也; 火中生液, 名曰真水。”在陰陽升降、水火交合的過程中, 肝臟和肺藏也需 要參與, “腎氣足而肝氣生, 肝氣既生, 以絕腎之餘陰, 而純陽 之氣上升者也 ……心液到而肺液生, 肺液既生, 以絕心之餘陽, 而純陰之液下降者也。”(《道藏》4：665) 為免影響內丹修煉, 全真道徒似乎不應捐贈活體腎臟、部分肝臟或部分肺藏。但全真 道同時主張先人後己及相信輪迴, 實際上大可今生先捐贈活體器 官利人, 今生內丹修煉即使或有妨礙, 但以後仍有多生多世的修 行機會, 仿傚佛陀割肉餵鷹、地藏誓不成佛, 豈非美事? 及後, 內丹原理被應用到神霄派雷法及東華派濟煉科儀之中，行持此等 科法的道士, 本來就是為了濟世利人, 捐贈活體器官利人雖然會 削弱敷演科法的效力，但奪彼與此，何其偏也？

\section{三、建構具最大共通性的現代教義詮釋}

上述兩章梳理了歷代各派與器官捐贈可能相關的教理，本章 嘗試宏觀地綜合之，並從中抽取出道教的宗教獨特屬性，繼而以 之為基礎, 嘗試對器官捐贈建構具最大共通性的現代教義詮釋。 本文認為道教的宗教獨特屬性如下：

一、道教的終極關懷是成仙，因為道教認為人生的本質是 “樂”, 而健康的精神和青春的肉體是快樂的根源, 盡量延長壽 命和保持年輕狀態是大多數派別的共同追求。道教的宗教性則在 於, 它同時相信修煉變化後的精神和肉體, 可享有超自然而仍能 與世人溝通的無限生命, 各派所不同的只是追求此終極關懷的方 法。

二、道教大多服從最新的科學研究成果。各派身體觀雖然多 元, 但對身體理解多來自於長期的工夫修養。(林永勝 2013，28) 金 
丹道的煉丹術其實是當時最先進的 “科學”，爐火燒煉鉛录其實 是樸素的化學實驗; 而放棄燒煉鉛采金丹, 轉為以神燒煉精氣結 成內丹, 則是尊重鉛永金丹實驗失敗的表現; 今天看來房中派還 精補腦狀甚愚昧, 但所依的乃是當時中醫 “腎藏精, 精生髓” 及

“腦為髓海” 的藏腑五行 “科學” 理論; 全真派的取坎填離大小 周天以煉內丹, 所行經的任督二脈, 也符合當時中醫的經絡 “科 學” 理論。

三、道教善於屈服於社會主流道德倫理價值觀。學者甚至將 六朝道教發展史命名為屈服史。(葛兆光 2003) 東漢原始天師道奉 行含有性交成份的入教儀式 “上清黃書過度儀” 為根本大法, 但 北朝時寇謙之改革天師道時, 為了迎合統治階層的道德倫理, 主 動革除這一項 “三張偽法” ; 為應對佛教盛行, 東晋葛巢甫造構 靈寶經, 吸收業報輪迴等社會主流價值觀; 南宋淨明道和金元全 真道面對理學和禪宗的心性之論, 便以三教合一的手段調整自身 教義, 全真道甚至徹底放棄保存現世肉身以成仙的原教旨道教信 仰。

基於以上道教特性, 本文嘗試建構具最大共通性的器官捐贈 現代教義詮釋如下：

首先, 回應上述第一點, 現今道教普遍依然相信人生是樂, 追求延壽消災, 為此他們信奉北斗、太歲、斗母等星斗神, 現行 以源自宋元玄靈派的《太上玄靈北斗本命延生真經》為核心的星 斗信仰, 既受正一道全真道等主要派別共同信奉, 斗母又由於是 北斗及太歲之母而統攝二者, 在各地華人道觀和廟宇舉足輕重 (余 劍龍 2011，1-2), 有學者甚至稱之為“泛亞女神” (謝世維 2012， 1)。同為玄靈派的斗母信仰根本經典《太上玄靈斗姆大聖元君本 命延生心經》對輪迴主體 “隗” 的記載, 足以成為現今道教共同 考慮器官捐贈議題的起點。經中對魄的記載為 “斗姆……生諸天 眾月之明, 為北斗眾星之母, 斗為之隗, 水為之精, 主生人身…… 是以人身, 面有七憿, 內應乎心, 隗有七真, 受隗於斗。”（《道 
藏》 $11 ： 345)$ 經文中人體的七隗對應天界中心的北斗七星, 而七 星又是創造人類生命的大女神斗母的七魄, 人身七魄因而具有上 述宇宙中心原型的內涵。“是以人身, 面有七竅, 內應乎心, 隗 有七真” 對應 “受隗於斗”這種 “人身：體表七竅/ 心藏七孔/ 無形七魄一中天：北斗七星” 的 “小宇宙一大宇宙” 對應關 係定位於中心, 七隗作為控制人身的中心和輪迴主體, 也位於肉 體臓腑的中心——臟。

第二, 回應上述第二點, 道教大多服從最新的科學研究成果。 本文認為先民對神魂魄的想像, 源於樸素的生活觀察, 包括自我 意識、思想情感記憶等精神活動; 認為神魂魄可以離開身體或死 後仍暫存遺體內, 可能是出於對夢境的感受或對死後肢體仍有反 射動作的觀察而來。如果認同上述説法, 對照現代科學, 其實神 魂魄指的是腦髓控制的思想意識記憶感受以及自律神經活動。既 然現代醫學已證實腦髓才是人體中樞而非心臟, 因此上述經中的 小大宇宙對應關係, 大可重新詮釋為 “人身：腦髓/ 七魄一一 天：七星”。科學上神魂隗與神經功能完全對等; 宗教上它們更 是輪迴主體, 相信輪迴的道教徒大可認為腦髓控制的思想意識記 憶感受加上生前思言行為的記載, 能成為非物質的存在物, 在死 後脱離肉體而獨立存在並擔當輪迴轉世的主體。即使堅持這種生 命信仰, 與本文提出的器官移植現代教義詮釋並不相悖, 因為輪 迴主體居於腦髓, 活體或遺體器官捐贈均不會對捐贈者或受贈者 的轉世投胎有負面影響。

第三，回應上述第三點，道教善於屈服於主流道德倫理價值 觀。現今維護人權和同理心均是全球主流道德倫理價值觀。在個 人權利和公眾利益之間需要平衡, 尊重個人主動性的遺體器官捐 贈意願, 如上文整理可以避免妨礙屍解仙和太陰煉形等假死成仙 的可能; 也可令相信行善積功和慈悲濟人者實踐他們的同理心。 活體器官捐贈方面, 則各教派因其修行方法差異而對器官有不同 的生命想像, 如視個人權利多於利益他人, 天師道要五臟無損、 
上清派唯獨不可缺失一腎; 如視利益他人多於個人考慮, 活體器 官捐贈可為太平道金丹道積善功、淨明道行大乘、全真道踐真行、 靈寶派無量度人、東華派神霄派濟世救民。

\section{四、餘論}

最後, 道教並非如天主教有教廷對應現代處境統一而權威地 重新詮釋教義, 比較像基督新教堂會以個別宮觀廟堂形式獨立運 作。即使台灣有分香傳統、香港有道教聯合會、內地有宗教法例 和官方機構、天師祖庭有正一授籙、白雲觀有全真放戒, 但上述 組織或有大方向式的方針指引, 卻未有條陳規定具體教義對應現 代處境。而且, 自晚唐五代以來已有宮觀體制外道士或小團體自 修的現象。(李平, 2014) 自修道士更可按個人的感應和體悟, 選 擇信奉的經典、修法和教義詮釋。因此, 本文透過重新詮釋而建 構的、關於器官捐贈的現代共同教義, 只是拋磚引玉的野人獻曝 而已。體制內道士自會依從其降鸞神仙、祖師住持的聖訓; 體制 外道士則大可根據個人信仰自行詮釋教義, 或從上述歷代各派別 教義中任選一二, 作為自身對器官捐贈的所持態度。

\section{參考文獻 References}

: 《道藏》, 文物出版社、上海書店、天津古籍出版社聯合出版, $1988^{\circ}$ Daozang (Daoist Canon) (Wenwu Chubanshe, Shanghai Shudian, Tianjin Guji, 1988).

王 明: 《老子河上公章句考》北京: 北京大學出版部, $1948 \circ$ WANG Ming. Ho Shang-Kung Commentaries on the Lao-Tzu (Beijing: Peking University Press, 1948).

王 明:《抱朴子內篇校釋》, 北京: 中華書局, 1980 ${ }^{2}$ WANG Ming. Collation and Annotation of the Inner Chapters of the Book of the Master who Embraces Simplicity (Beijing: Zhonghua Book Company, 1980).

王明編: 《太平經合校》, 北京: 中華書局, 1960。WANG Ming (eds). Collated Edition of the Taipingjing (Beijing: Zhonghua Book Company, 1960). 
余劍龍：〈斗母研究〉, 廣州: 中山大學哲學系宗教學博士論文, 2011。 YU Kim-lung. "A Study of the Dipper Mother," (Guangzhou: Doctoral Degree Thesis, Religion Studies, Department of Philosophy, 2011).

李 平: 《宮觀之外的長生與成仙一一晚唐五代道教變遷研究》, 北京 中央編譯出版社, 2014 ○ LI Ping. Eternal life and Becoming Immortal outside Temple: A Study on the Transformation of Taoism in Late Tang and Five Dynasties (Beijing: Central Compilation \& Translation Press, 2014).

林永勝: 〈佛道交融視域下的道教身體觀——重玄學派為中心〉, 《輔 仁宗教研究》, 第 27 期, 2013 年秋, 頁 1-34。LIN Yung-Shen. “The Body in Daoism: the Daoist-Buddhist Syncretism of the Chongxuan School," Fujen Religious Studies, 2013 (XXVII.2):1-34.

林富士：〈《太平經》的神仙觀念〉, 《中央研究院歷史語言研究所集 刊》第 80 本, 第 2 份, 頁 217-263。LIN Fu-Shih. “The Idea of the Transcendents in the Taiping Jing," Bulletin of the Institute of History and Philology Academia Sinica 2009 (LXXX.2):217-263.

耶律亞德著, 楊儒賓譯：《宇宙與歷史：永恒回歸的神話》, 台北：聯 經出版事業, 2000 。Eliade M. The Myth of the Eternal Return: Archetypes and Repetition, translated by YANG Rur-bin (Taipei: Linking Publishing, 2000).

香港器官移植基金會：《器官捐贈，以愛承傳》, 香港：香港器官移植 基金會, 2017 。Hong Kong Organ Transplant Foundation. Organ Donation: The Legacy of Love (Hong Kong: Hong Kong Organ Transplant Foundation, 2017).

張 穎：〈導言：換頭術、嗎啡治療、病人自主權〉, 《中外醫學哲學》 第 16 卷, 第 1 期, 2018 年, 頁 1-10。ZHANG, Ellen Y. "Introduction: Head Transplant, Morphine Treatment and Patient Autonomy," International Journal of Chinese \& Comparative Philosophy of Medicine 2018 (XVI.1):1-10.

梁辰、鄧芯：〈受苦的心識——從大乘佛教觀點看頭顱移植〉, 《中外 醫學哲學》, 第 16 卷, 第 1 期, 2018 年, 頁 45-59。LIANG Chen, DENG Rui. "The Suffering Consciousness: Head Transplantation from the Perspective of Mahayana Buddhism," International Journal of Chinese \& Comparative Philosophy of Medicine 2018 (XVI.1):45-49. 葉貴良：《敦煌本〈太玄真一本際經〉輯校》, 成都：巴蜀書社, 2010。 YE Guiliang. Collated edition of Dunhuang, Version of the Scripture on the Fundamental Occasion (Chengdu: Bashu Book Society, 2010). 葛兆光：《屈服史及其他：六朝隋唐道教的思想史研究》, 北京：生活. 讀書·新知三聯書店, $2003 \circ \mathrm{GE}$ Zhao-guang. A History of Subjugation and Other Things: An Intellectual History of Daoism during the Six Dynasties and Sui-Tang Period (Beijing: SDX Joint Publishing Company, 2003).

謝世維：〈古靈寶經中的大乘之道：論中古時期道教經典型態之轉變〉, 《成大中文學報》, 第 36 期, 2012.3, 頁 1-36 ${ }^{\circ}$ HSIEH Shu-Wei. “The Way of Great Vehicle in Early Lingbao Scriptures: The Transformation of Daoist Scriptures in Medieval China," Journal of Chinese Literature of National Cheng Kung University XXXVI (2012.3), pp. 1-36. 
謝世維：〈泛亞女神的中國面貌：摩利支天文本的流傳與在地化〉, 台

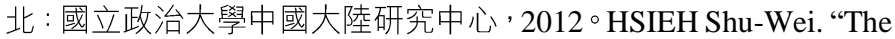
Face of the Pan-Asian Goddess: the Transmission and Localization of text of Marci," (Taipei: Center for China Studies National Chengchi University, 2012).

韓吉紹：〈自殺求仙：道教尸解與六朝社會〉, 《文史》, 2017 年第 1 期 , 頁 29-49 ○ HAN Jishao. "Suicide to Pursuit Immortality: Apotheosis of Taoism and Society of the Six Dynasties," Literature and History 2017 (1):29-49.

饒宗頤: 《老子想爾注校箋》, 香港: 作者自印, 1956JAO Tsung-i. Collation of the Xiang'er Commentary to Laozi (Hong Kong: JAO Tsung-I, 1956). 